\title{
The Use of Ripasudil Hydrochloride Hydrate in Endothelial Decompensation - A Case Series
}

\section{Pedro Manuel Baptista ${ }^{*}$, Nelson Sena ${ }^{4-6}$, Fernando Faria-Correia ${ }^{2-4}$, Marcella Salomã $0^{4,7-10}$ and Renato Ambrósio Jr $\mathbf{r}^{4-9}$}

${ }^{1}$ Ophthalmology Department, Centro Hospitalar Universitário do Porto, Portugal

${ }^{2}$ Ophthalmology Department, Hospital de Braga, Portugal

${ }^{3}$ Universidade do Minho, Minho, Portugal

${ }^{4}$ Rio de Janeiro Corneal Tomography and Biomechanics Study Group, Rio de Janeiro, RJ, Brazil

${ }^{5}$ Department of Cornea and Refractive Surgery, Instituto de Olhos Renato Ambrósio, Rio de Janeiro, Brazil

${ }^{6}$ Department of Opthalmology, Federal University of the State of Rio de Janeiro (UNIRIO), Rio de Janeiro, Brazil

${ }^{7}$ Federal University of São Paulo (UNIFESP), São Paulo, Brazil

${ }^{8}$ Brazilian Study Group of Artificial Intelligence and Corneal Analysis - BrAIN, Rio de Janeiro and Maceió, Brazil

${ }^{9}$ Instituto de Olhos Renato Ambrósio, Rio de Janeiro, Brazil

${ }^{10}$ Instituto Benjamin Constant, Rio de Janeiro, Brazil

*Corresponding Author: Pedro Manuel Baptista, Ophthalmology Department,

Centro Hospitalar Universitário do Porto, Portugal.
Received: January 15, 2021

Published: February 08, 2021

(C) All rights are reserved by Pedro Manuel

Baptista., et al.

\begin{abstract}
Purpose: To describe the preliminary clinical experience, including corneal structural response to Ripasudil hydrochloride hydrate (Glanatec ${ }^{\circledR}$ ophthalmic solution $0.4 \%$, Kowa Company, Ltd, Japan) in cases of corneal endothelial dysfunction.

Methods: Retrospective observational study based on patients' clinical records treated with Ripasudil hydrochloride hydrate three times a day for different conditions of corneal endothelial dysfunction. Outcome measures included clinical data with subjective response, uncorrected distance visual acuity (UDVA, Snellen), central corneal thickness (CCT, $\mu \mathrm{m}$ ) measured with rotating Scheimpflug tomography (Pentacam HR, Oculus ${ }^{\circledR}$, Wetzlar, Germany), intraocular pressure (IOP, mmHg) measured with dynamic Scheimpflug imaging (Corvis ST, Oculus ${ }^{\circledR}$, Wetzlar, Germany) and endothelial cell density (ECD, cells $/ \mathrm{mm}^{2}$ ) measured with EM-4000 Specular Microscope (Tomey ${ }^{\circledR}$, Nuremberg, Germany).

Results: Five patients were analyzed, four women and one man, with a mean age of $74.2 \pm 12.4$ years. Two cases of Fuchs' endothelial corneal dystrophy (FECD), two of pseudophakic bullous keratopathy (PBK) and one of penetrating keratoplasty graft decompensation (PKGD) were included. Treatment duration until results range from 1 to 6 months (mean 3.4 months). A good response was observed in both the cases of FECD and PBK. Despite a good initial response, a bad result was observed in the PKGD case. There were no ocular or systemic side effects related.

Conclusion: The ROCK inhibitor Ripasudil hydrochloride hydrate is potentially effective in the treatment of different forms of corneal endothelial decompensation. Our work shows the short-term efficacy and safety of topical Ripasudil in the management of FECD and PBK derived endothelial decompensation. More studies with large samples and longer follow-up are needed.

Keywords: Ripasudil Hydrochloride Hydrate; ROCK Inhibitor; Fuchs Endothelial Corneal Dystrophy; Pseudophakic Bullous Keratopathy; Corneal Endothelium Decompensation
\end{abstract}




\section{Introduction}

Rho-associated kinase (ROCK) is a serine/threonine-protein kinase involved in the regulation and modulation of many cell signal pathways, namely shape and size, smooth muscle contraction, cell adhesion, cell stiffening, and extracellular matrix reorganization. These factors are determinants of Aqueous Humor (AH) outflow via the trabecular pathway, a ROCK inhibitor, Ripasudil hydrochloride hydrate (Ripasudil) (Glanatec ${ }^{\circledR}$ ophthalmic solution 0.4 \%, Kowa Company, Ltd, Japan), was approved in Japan in 2014 to be used in glaucoma patients [1]. On the other hand, knowing the referred potential general cellular effects, these Rho Kinase inhibitors have been tested for some years for the use on the corneal endothelium healing, as this tissue has a very limited proliferation capacity and, therefore, any structural damage is repaired by the migration of remaining corneal endothelium cells to the afflicted area, with a resulting drop in endothelium density [2].

The group of Okumura., et al. reported back in 2009 the effect of the selective ROCK inhibitor Y-27632 in promoting in vitro cell proliferation of cultured primate endothelial cells [3]. In 2011, the same group demonstrated that its topical application in the form of eye drops could enhance both in vitro (monkey model) and in vivo (rabbit) corneal endothelial wound healing [4] and rapidly moved further to a pilot trial testing the same eye drops $(10 \mathrm{mM}$ of Y-27632 applied six times a day for 7 days) on human patients with corneal endothelial dysfunction [5] either with central or diffuse corneal edema due to corneal decompensation associated with Fuchs Endothelial Corneal Dystrophy (FECD). In this study [5] the authors suggest that ROCK inhibitor eye drops enhance corneal endothelial wound healing by promoting residual corneal endothelial cells proliferation, as long as some relatively healthy cells remain, as there was no substantial effect in the more advanced cases. Nevertheless, the only current therapeutic choice approved for treating corneal endothelial decompensation is corneal transplantation using donor corneas [2].

The evolution of surgical procedures has enabled less invasive treatment of corneal endothelial decompensation with better clinical outcomes. However, these surgeries still have associated issues, such as the difficulty of the actual surgical technique, graft rejection, acute and chronic cell loss, and the shortage of donor corneas. Therefore, new and innovative therapies are still in great demand. Currently, one research direction focuses on tissue engineering therapy, and another is pharmaceutical treatment, with two proposed methods of delivery of ROCK inhibitors to heal the corneal endothelium, including topical eye drops and an anterior chamber injection with cultured endothelial cells [2].
The aim of the present study is to describe the preliminary clinical experience, including corneal structural response to $\mathrm{Ri}$ pasudil hydrochloride hydrate in cases of corneal endothelial dysfunction.

\section{Materials and Methods}

This is a retrospective observational study based on patients' clinical records treated with Ripasudil three times a day for different conditions of corneal endothelial dysfunction. The study adhered to the tenets of the Declaration of Helsinki. Approval was obtained from the 'Federal University of São Paulo (UNIFESP) ethics committee, nr: 2568.770/2018. Informed consent for the off-label treatment of corneal edema with Ripasudil and for the use of anonymized images and clinical data were obtained from all patients.

Outcome measures included clinical data with subjective response, uncorrected distance visual acuity (UDVA, Snellen), central corneal thickness (CCT, $\mu \mathrm{m}$ ) measured with rotating Scheimpflug tomography (Pentacam HR, Oculus ${ }^{\circledR}$, Wetzlar, Germany), intraocular pressure (IOP, mmHg) measured with dynamic Scheimpflug imaging (Corvis ST, Oculus ${ }^{\circledR}$, Wetzlar, Germany) and central endothelial cell density (ECD, cells $/ \mathrm{mm}^{2}$ ) measured with Tomey ${ }^{\circledR}$ EM-4000 Specular Microscope (Nidek ${ }^{\circledR}$, Nagoya, Japan).

\section{Results}

Five consecutive patients were analyzed, four women and one man, with a mean age of $74.2 \pm 12.4$ years. Mean treatment duration until results was 3.4 months [1-6]. Two cases had Fuchs' endothelial corneal dystrophy (FECD), two had pseudophakic bullous keratopathy (PBK) and one had penetrating keratoplasty graft decompensation (PKGD). There were no ocular or systemic side effects related. Table 1 summarizes all cases.

\section{Case 1}

An 80-year old female with systemic hypertension and FECD grade 5 (Krachmer) diagnosis with a baseline ECD of 2704 cells/ $\mathrm{mm}^{2}$ started a clinical picture of corneal decompensation after uneventful cataract surgery, with corneal edema (CCT $688 \mu \mathrm{m}$ ) and UDVA decreased to 20/40. Ripasudil 3 times a day was initiated and after 2 months of treatment, the corneal edema cleared, with a CCT decrease of $132 \mu \mathrm{m}$ and IOP decrease of $3 \mathrm{mmHg}$. UDVA improved to $20 / 30$, but the ECD was not quantifiable. Ripasudil was discontinued and after 9 months the clinical picture remained stable, with the CDVA reaching 20/20. 


\begin{tabular}{|c|c|c|c|c|c|c|c|c|c|c|c|c|c|}
\hline & Age & $\begin{array}{c}\text { Gen- } \\
\text { der }\end{array}$ & $\begin{array}{c}\text { Pa- } \\
\text { thol- } \\
\text { ogy }\end{array}$ & $\begin{array}{c}\text { Initial } \\
\text { UDVA } \\
\text { (Snellen) }\end{array}$ & $\begin{array}{l}\text { Ini- } \\
\text { tial } \\
\text { CCT } \\
\text { (um) }\end{array}$ & $\begin{array}{c}\text { Initial } \\
\text { IOP } \\
\text { (mm } \\
\text { Hg) }\end{array}$ & $\begin{array}{l}\text { Initial } \\
\text { ECD } \\
\text { (cells/ } \\
\text { mm2) }\end{array}$ & $\begin{array}{c}\text { Treat- } \\
\text { ment } \\
\text { duration } \\
\text { until } \\
\text { results } \\
\text { (months) }\end{array}$ & $\begin{array}{c}\text { Final } \\
\text { UDVA } \\
\text { (Snel- } \\
\text { len) }\end{array}$ & $\begin{array}{c}\text { Final } \\
\text { CCT } \\
\text { (um) }\end{array}$ & $\begin{array}{c}\text { Final } \\
\text { IOP } \\
\text { (mmHg) }\end{array}$ & $\begin{array}{l}\text { Final } \\
\text { ECD } \\
\text { (cells/ } \\
\text { mm2) }\end{array}$ & $\begin{array}{c}\text { Side } \\
\text { ef- } \\
\text { fects }\end{array}$ \\
\hline Case 1 & 80 & Female & FECD & $20 / 40$ & 688 & 11.5 & 2704 & 2 & $20 / 20$ & 552 & 8.5 & NQ & None \\
\hline Case 2 & 83 & Female & FECD & $\mathrm{CF}$ & 713 & NQ & NQ & 3 & $20 / 50$ & 480 & 13 & 981 & None \\
\hline Case 3 & 58 & Female & PBK & $20 / 25$ & 628 & 10.5 & 2194 & 6 & $20 / 20$ & 533 & 11 & NM & None \\
\hline Case 4 & 86 & Female & PBK & $20 / 40$ & 578 & 13 & 725 & 1 & $20 / 30$ & 558 & 12 & NM & None \\
\hline Case 5 & 64 & Male & PKGD & $20 / 400$ & 603 & 11 & 2545 & 4 & $20 / 400$ & 763 & 10 & NQ & None \\
\hline
\end{tabular}

Table 1: Summary of all cases.

Phaco: Phacoemulsification with Intraocular Lens Placement; NQ: No Quantifiable; NM: No Measured; CF: Counting Fingers; PKGD: Penetrating Keratoplasty Graft Decompensation.

\section{Case 2}

An 83-year old female with Diabetes Mellitus, systemic hypertension, dyslipidemia, and FECD grade 5 (Krachmer) diagnosis with central guttata, who underwent cataract surgery 15 years before, started a clinical picture of corneal decompensation with corneal edema and vision decreased to counting fingers (CF). After the poor response to topical hypertonic $5 \%{ }^{\circledR}$, maintaining a CCT of $713 \mu \mathrm{m}$ with the impossibility to measure the IOP and the ECD, Ripasudil 3 times a day treatment was added. The corneal edema started to clear after 1 month. After 3 months of treatment, a CCT decrease of $233 \mu \mathrm{m}$ to $480 \mu \mathrm{m}$ was observed, with UDVA improved to $20 / 50$ and already quantifiable ECD (981 cells $/ \mathrm{mm}^{2}$ ). The patient maintained the treatment for more than seven months and two months after stopping the cornea remained without edema.

\section{Case 3}

A 58-year old otherwise healthy female initiated a clinical picture of PBK with ECD of 2194 cells $/ \mathrm{mm}^{2}$, a CCT of $628 \mu \mathrm{m}$, and UDVA of $20 / 25$, one month after uneventful cataract surgery. Ripasudil 3 times a day was initiated and after 6 months of treatment, corneal edema cleared, with a CCT of $533 \mu \mathrm{m}$ and UDVA of 20/20. The ECD was not measured.

\section{Case 4}

An 86-year old Type 2 diabetic female with a history of cataract surgery and Descemet stripping endothelial keratoplasty (DSAEK) due to PBK in one eye, has been proposed to cataract surgery in the other eye, with UDVA of 20/200 and endothelium at risk for PBK with an ECD of 725 cells $/ \mathrm{mm}^{2}$. Corneal edema was observed four days after the procedure (CCT $578 \mu \mathrm{m}$ ) with UDVA of 20/40. Treatment with Ripasudil 3 times a day was started immediately. After 1 month of treatment, corneal edema cleared, with a decrease of
$20 \mu \mathrm{m}$ in the CCT and UDVA improvement to 20/30. The ECD was not measured. Ripasudil was stopped after 3 months and after almost one year from the procedure, the clinical picture remained stable.

\section{Case 5}

A 64-year-old type 2 diabetic, hypertense and hyperuricemic male initiated chronic graft decompensation from a previous penetrating keratoplasty (PK) for bullous keratopathy, seven years after uneventful cataract surgery. After a poor response to Hypertonic $5 \%{ }^{\circledR}$, with a CCT of $603 \mu \mathrm{m}$, ECD of 2545 cells $/ \mathrm{mm}^{2}$, and UDVA of 20/400, Ripasudil 3 times a day was added. Besides some improvement after 4 months of treatment, with a decrease in the CCT from $603 \mu \mathrm{m}$ to $559 \mu \mathrm{m}, 1$ month after that, further decompensation was observed, with the CCT reaching $763 \mu \mathrm{m}$, the same UDVA, and nonquantifiable ECD.

\section{Discussion}

\section{Endothelial cell density}

Although the capacity of promoting in vitro and in vivo cell proliferation of endothelial cells, the known variability in the measurements, and the difficulty to obtain reliable values in pathologic corneas makes the ECD a worse parameter than CCT for the evaluation of response.

\section{Fuchs' corneal dystrophy}

The current mainstay method of treatment for FECD is a corneal transplant, as cell death is one of the major contributing factors of disease progression. The use of a drop solution of ROCK inhibitor is effective in the early stages of disease [2]. On the other hand, there were also a report [6] from 2013 of a 2-year follow-up success in a more advanced stage: in this case, the patient had mid periphery 
ECD of 757 cells $/ \mathrm{mm}^{2}$ and underwent corneal endothelial denudation in the central pupillary region followed by the topical administration of $50 \mathrm{~mL}$ of $10 \mathrm{mM}$ ROCK inhibitor, Y-27632 as eye drops, repeated 6 times daily for 7 days.

Another promising treatment option being studied is the use of these drugs as an injection in combination with cultured corneal endothelial cells, increasing the adhesion of the cultured cells to the substrate and promoting corneal endothelial regeneration and restoration of corneal transparency. This technique has been tested in animal models of corneal endothelial decompensation without any sign of harmful effects [7]. The present study showed a good clinical response in both FECD cases (case 1 and case 2) with important improvement in anatomical parameters and UDVA.

\section{In risk endothelium and acute corneal trauma}

PBK is one of the leading causes of corneal transplantation in many countries $[8,9]$. The density of endothelial cells available for redistribution is the main factor that determines whether the cornea becomes transparent or undergoes corneal decompensation.

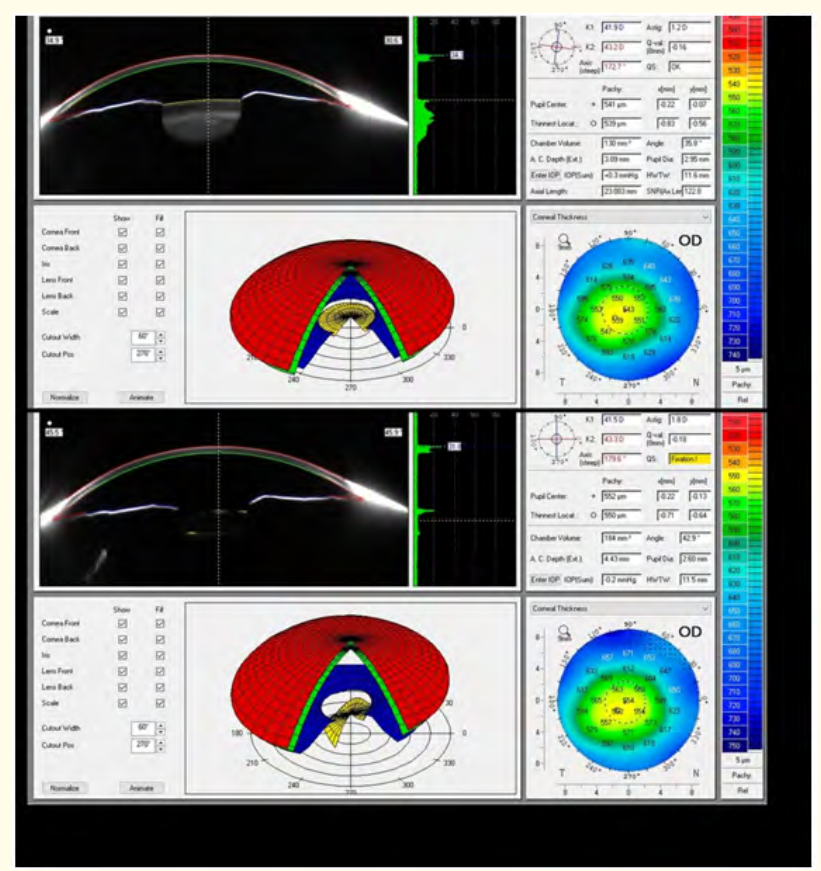

Figure 1: Case 1: Scheimpflug image (Pentacam $\AA)$, baseline (before phacoemulsification) and 9 months after the procedure (7 months after medication cessation).

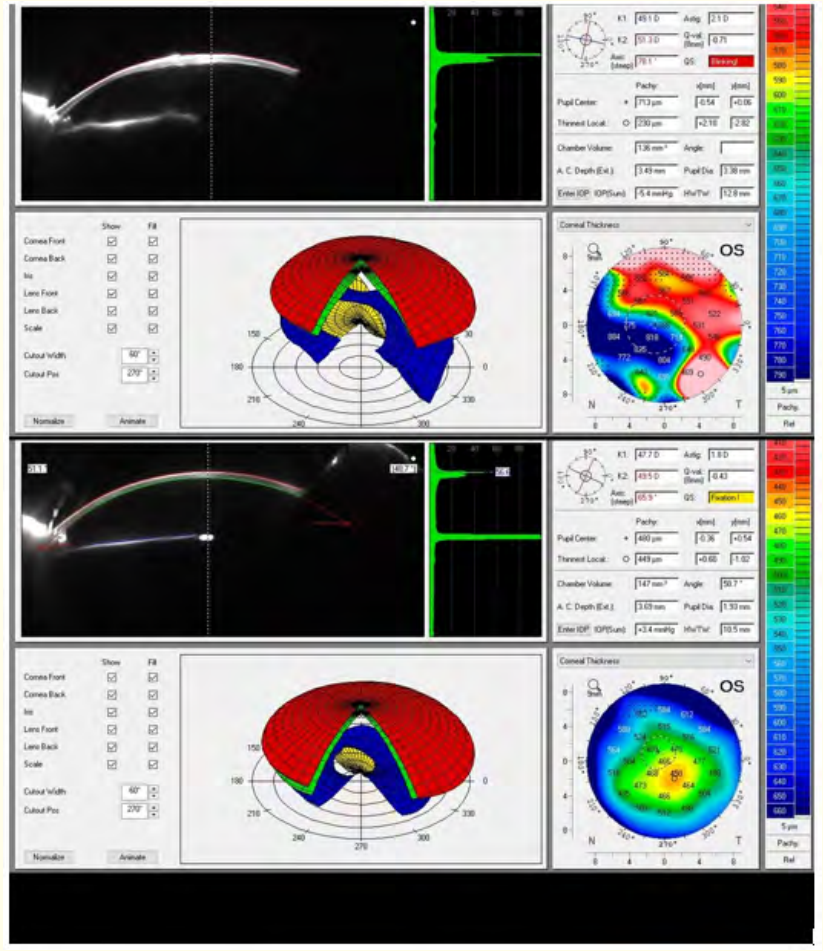

Figure 2: Case 2: Scheimpflug image (Pentacam $®)$, before treatment and after 3 months of treatment.

In 2015, the group of Okumura., et al. [10] reported preliminary results on three patients who developed severe corneal edema and corneal haziness, after cataract surgery: in two patients, more than half of Descemet's membrane area was detached accidentally and was removed during phacoemulsification and in the other one, almost one half of the corneal endothelial area was damaged due to trauma during the dissection of one iris cyst during cataract surgery. For all patients, $1 \mathrm{mM}$ of Y-27632 was administered in the form of an eye drop six times daily for 4 months, followed by four times daily for 2 additional months. Within one to two months, there was the recovery of corneal transparency, showing an increase in corneal endothelial cell density in all three patients. These preliminary findings of the safety and effectiveness of ocular topical ROCK inhibitor support their use as a treatment for corneal endothelial damage. The present study found good clinical response in both PBK cases (cases 3 and 4) with a rapid response in the case with less baseline ECD (case 4), in contrast to the worse outcome reported recently [11] after twelve weeks of treatment with one daily drop of the topical ROCK inhibitor, Netarsudil ${ }^{\circledR}$. In 
the case of chronic PKGD, despite high baseline graft ECD, after the initial clinical response, in line with the reported in two cases in the same study [11], further decompensation was observed in the present study (case 5)

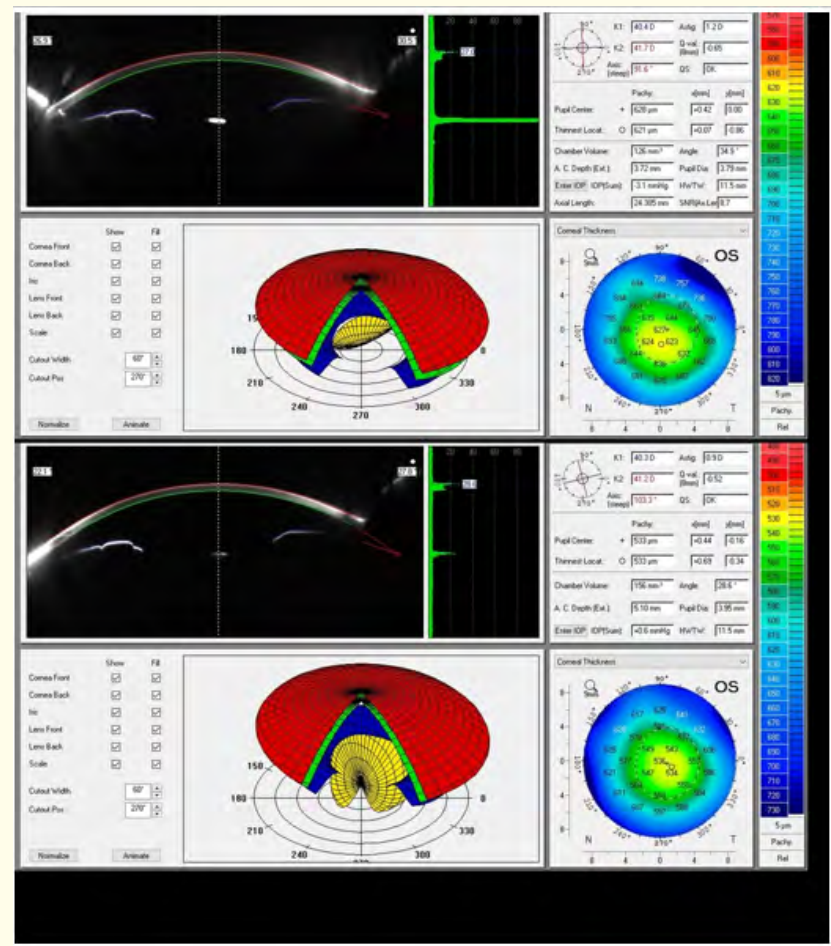

Figure 3: Case 3: Scheimpflug image (Pentacam ${ }^{\circledR}$ ), before treatment and after 6 months of treatment

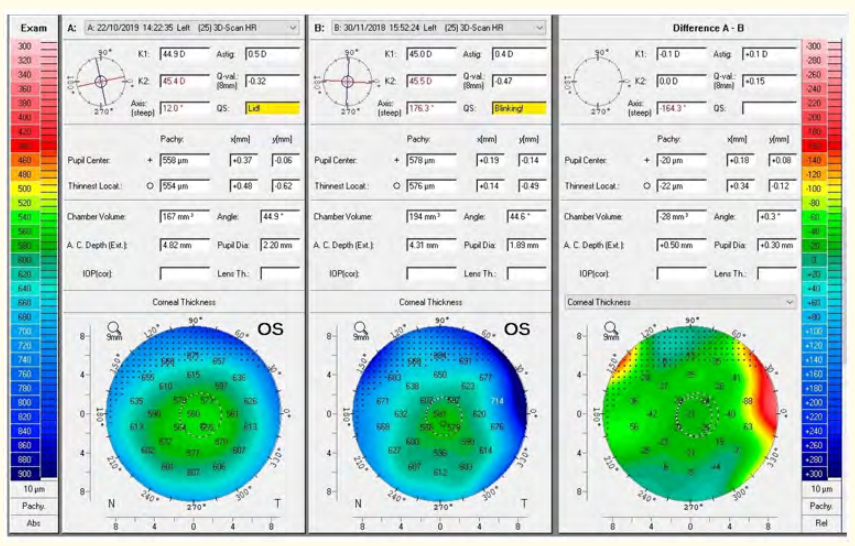

Figure 4: Case 4: Corneal thickness comparative analysis (Pentacam $\AA$ ), before treatment and 8 months after treatment cessation.

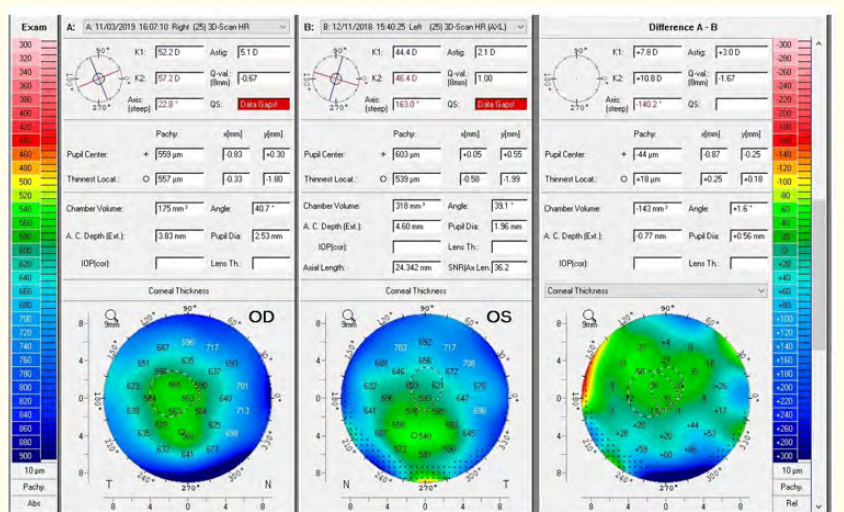

Figure 5: Case 5: Corneal thickness comparative analysis (Pentacam $\AA$ ), before treatment and after 4 months of treatment.

\section{Adverse effects}

A large series of 103 glaucomatous eyes [12] in a long-term Ripasudil treatment showed Blepharitis has the most common reason for discontinuation. There was found an association with the history of allergy to other glaucoma topical medications and most cases resolved spontaneously after that. Dose-dependent conjunctival hyperemia is usually seen in most the patients. Non-dose-dependent conjunctival hemorrhage was also reported. Additionally, no other side effects have been reported yet. We did not observe any side effects during the follow-up in our series.

\section{Conclusion}

The ROCK inhibitor Ripasudil hydrochloride hydrate is potentially effective in the treatment of different forms of corneal endothelial decompensation. Our work shows the short-term efficacy and safety of topical Ripasudil in the management of FECD and PBK derived endothelial decompensation. More studies with large samples and longer follow-up are needed.

\section{Bibliography}

1. Moshirfar M., et al. "Use of Rho kinase Inhibitors in Ophthalmology: A Review of the Literature". Medical Hypothesis, Discovery and Innovation Ophthalmology Journal 7 (2018): 10111.

2. Okumura N., et al. "Application of Rho Kinase Inhibitors for the Treatment of Corneal Endothelial Diseases". Journal of Ophthalmology 2017 (2017): 2646904.

3. Okumura N., et al. "Enhancement on primate corneal endothelial cell survival in vitro by a ROCK inhibitor". Investigative Ophthalmology and Visual Science 50 (2009): 3680-3687. 
4. Okumura N., et al. "Enhancement of corneal endothelium wound healing by Rho-associated kinase (ROCK) inhibitor eye drops". The British Journal of Ophthalmology 95 (2011): 10061009.

5. Okumura N., et al. "The ROCK inhibitor eye drop accelerates corneal endothelium wound healing". Investigative Ophthalmology and Visual Science 54 (2013): 2493-2502.

6. Koizumi N., et al. "Rho-associated kinase inhibitor eye drop treatment as a possible medical treatment for Fuchs corneal dystrophy". Cornea 32 (2013): 1167-1170.

7. Okumura N., et al. "Rho kinase inhibitor enables cell-based therapy for corneal endothelial dysfunction". Scientific Reports 6 (2016): 26113.

8. Eye Banking Statistical Report, Eye Bank Association of America, Washington D.C (2015).

9. Shimazaki J., et al. "National survey on bullous keratopathy in Japan”. Cornea 26 (2007): 274-278.

10. Okumura N., et al. "Effect of the Rho Kinase Inhibitor Y-27632 on Corneal Endothelial Wound Healing". Investigative Ophthalmology and Visual Science 56 (2015): 6067-6074.

11. Davies E. "Case Series: Novel Utilization of Rho-Kinase Inhibitor for the Treatment of Corneal Edema". Cornea 40 (2021): 116-20.

12. Saito H., et al. "Long-term Side Effects Including Blepharitis Leading to Discontinuation of Ripasudil". Journal of Glaucoma 28 (2019): 289-293.

\section{Assets from publication with us}

- Prompt Acknowledgement after receiving the article

- Thorough Double blinded peer review

- Rapid Publication

- Issue of Publication Certificate

- High visibility of your Published work

Website: www.actascientific.com/

Submit Article: www.actascientific.com/submission.php

Email us: editor@actascientific.com

Contact us: +919182824667

Citation: Pedro Manuel Baptista., et al. "The Use of Ripasudil Hydrochloride Hydrate in Endothelial Decompensation - A Case Series". Acta Scientific Ophthalmology 4.3 (2021): 20-25. 